\title{
Sujeto y subjetividad en las principales escuelas de psicoterapia sistémica: un estado del arte
}

\section{Sentido y criterios para la construcción de un estado del arte}

$S_{\text {ción documental y testimonial para abordar el conocimiento acu- }}^{\text {e entiende que un estado del arte es una modalidad de la investiga- }}$ mulado dentro de un campo específico del saber. En general, se sugiere que un estado del arte incluya contextualización, clasificación y categorización, pero aquí se tomarán como referentes algunos criterios propuestos por Foucault (1969) en La arqueología del saber. Se elige esta perspectiva porque permite comprender que un estado del arte no sigue una linealidad histórica que implique la desaparición de unas epistemes en favor de otras con pretensiones de novedad, sino más bien comprender la coexistencia de saberes alrededor de un campo que se nutre permanentemente en las interacciones contextuales que dan vida a los discursos y a las prácticas sociales. Es decir, se asume que si bien es ya universalmente reconocido el campo de la terapia familiar sistémica, es imposible abarcarlo en forma exhaustiva, pues desde el momento de su emergencia, o de su positividad como dice Foucault, han surgido variantes y disonancias cuya profundización excede los alcances de este texto. 
No sobra recordar que la arqueología foucaultiana es un instrumento para articular el análisis de las formaciones sociales, las formaciones epistemológicas y las posiciones del sujeto alrededor de un saber. Por su carácter descriptivo, aplica un método de disección del discurso a partir de la distinción de niveles, dominios, conceptos y procedimientos, con el fin de articular coyunturas que posibilitan el surgimiento de determinados discursos, en nuestro caso, la terapia sistémica y la forma como en ese campo se ha abordado la subjetividad.

La arqueología pretende definir los discursos en cuanto prácticas que obedecen a unas reglas y procesos complejos, observables y descriptibles, sin esperar encontrar la transición continua y lineal que une los discursos en una secuencia, ni la unicidad de los mismos, sino la diferenciación, el análisis de las contradicciones, las descripciones comparativas y la localización de las transformaciones dentro de ese campo. Esto significa, que las escuelas de terapia sistémica coexisten en el mundo y por tanto la pretensión de formular secuencias que definen como vigentes $\mathrm{u}$ obsoletas ciertas premisas y prácticas no es más que la expresión de las preferencias del observador que las describe.

Desde la perspectiva arqueológica, las relaciones causales se asignan al nivel del contexto y de su efecto sobre el sujeto parlante, después de definir las positividades donde aparecen y las reglas según las cuales han sido formadas esas positividades. Porque se supone que no se puede aplicar a priori un carácter evolutivo a los discursos, ni una búsqueda de sincronía, sino que al contrario el discurso se establece en una intemporalidad discontinua, aunque puedan localizarse vectores temporales de derivación de sus enunciados.

La arqueología asume que unas transformaciones contemporáneas, análogas y vinculadas, no remiten a un modelo único que impusiese a todos los discursos una forma también única de ruptura, entendiendo que ruptura es el nombre dado a las transformaciones que influyen en el régimen general de una o varias formaciones discursivas. Tampoco la arqueología se halla determinada por la "obra” como cristalización representativa de un momento o de un psiquismo que pueda ser típico de una época; más bien define unos tipos y unas reglas de prácticas discursivas que atraviesan obras individuales, a veces totalmente y otras parcialmente, 
con lo cual cuestiona el mito de la autoridad y la veneración del autor, y más aún la tentación de calificar la novedad como superioridad. Para nuestros efectos esto significa que aproximarse a la elaboración de un estado del arte de las escuelas de terapia sistémica exige reconocer los aportes de los autores destacados yendo más allá de las simpatías o las preferencias, para identificar la vigencia y la pertinencia de los conceptos y las metodologías que caracterizan sus escuelas.

La arqueología se define como una reescritura, una transformación pautada de lo que ha sido y se ha escrito y una descripción sistemática de un discurso-objeto. A diferencia de la historia de las ideas, no considera pertinente el asunto de la originalidad-trivialidad de los discursos, ni la búsqueda de sucesiones cronológicas, sino que le interesa la regularidad de los enunciados. La “época” tampoco es su unidad ni su base, ni su horizonte ni su objeto; si se refiere a ella es a propósito de prácticas discursivas determinadas y como resultado de sus análisis.

En su función de instrumento articulador del análisis de las formaciones sociales y de las descripciones epistemológicas, la arqueología muestra que hablar es hacer algo; que agregar un enunciado a una serie preexistente de enunciados implica unas condiciones, un contexto y unos motivos, y que más allá de la creatividad, requiere unas transformaciones en las prácticas sociales, de modo que el cambio en el discurso se da más allá del sujeto, de la conciencia y del autor.

El objeto de la arqueología es el análisis y la descripción de las formaciones discursivas, las cuales no pueden confundirse con disciplinas y no constituyen una ciencia sino un saber. Un saber es aquello de lo que se puede hablar en una práctica discursiva específica, un espacio donde el sujeto toma posición para hablar de los objetos de su discurso; es el campo de coordinación y de subordinación de los enunciados donde aparecen los conceptos, se definen, se aplican y se transforman, en relación con otros discursos y prácticas discursivas, en un curso que es irregular y heterogéneo.

A propósito de una formación discursiva se pueden describir cuatro momentos distintos para su emergencia: 1) aquel en el cual se individualiza y adquiere su autonomía, llamado umbral de positividad; 2) cuando un conjunto de enunciados pretende hacer valer unas normas 
de verificación y de cohesión y ejerce con respecto del saber una función dominante (de modelo, de crítica, de verificación), denominado umbral de epistemologización; 3) cuando esa figura epistemológica así dibujada obedece a cierto número de criterios formales y a determinadas leyes de construcción de las proposiciones, llamado umbral de cientificidad; 4) cuando puede definir los axiomas que como discurso científico le son necesarios, los elementos que utiliza, las estructuras proposicionales que le son legítimas y las transformaciones que acepta, conocido como umbral de formalización.

Según esos criterios, se diría que la terapia sistémica tiene el estatus de formación discursiva porque su existencia como saber específico es ya universalmente reconocida; se enmarca dentro de las epistemologías constructivista y construccionista; sigue sometiendo al escrutinio de la investigación y de la práctica, teorías y técnicas específicas, mediante métodos que ganan progresivamente diferenciación y posicionamiento en el terreno de las ciencias humanas y de la salud.

Con estos referentes, se analizan enseguida los planteamientos de tres escuelas de terapia sistémica que se considera han marcado diferencias significativas en el curso de este saber, como una ilustración que sirva de base para una comprensión de las variadas formas como se ha intentado aportar al desarrollo humano, desde estas formas discursivas, cuya aproximación al sujeto y al individuo han tenido distintos matices con sus respectivas consecuencias teóricas y paradigmáticas.

\section{El individuo y el sujeto en la terapia sistémica}

Se encuentran en la literatura de la terapia sistémica pocas referencias directas a las distinciones entre sujeto, subjetividad, individuo e identidad, por lo cual resultan interesantes los planteamientos de Trappeniers y Boyer (2004), terapeutas de los centros de estudio de la familia en Lille y Toulouse (Francia). Se preguntan estos autores si en la terapia sistémica conviene hablar de individuos en interacción o de sujetos en relación y para dar respuesta a estos interrogantes se remiten a la historia de las nociones de individuo y de sujeto. 
Fue a partir del Renacimiento y de la revolución francesa de 1789, cuando los humanos occidentales comenzaron a pensarse más como individuos; dejaron de ser vistos como hijos de Dios y siervos del monarca, para empezar a verlos como actores del mercado que funciona en un interjuego de contratos comerciales, donde solo cuenta la relación entre vendedor y comprador, haciendo abstracción de otros contextos donde participa la persona. En ese sentido, la noción de individuo es un artificio contable, la realización particular de una categoría general: una piedra, un geranio, un caballo, un ser humano, etc.; es una muestra estadística particular que se ha promovido a la condición de existencia en sí misma, sin contextualizar las relaciones de las que hace parte. Con respecto a los seres humanos, lo ilustra bien la Declaración Universal de los Derechos Humanos en sus artículos 2 y 3. Artículo 2: "toda persona tiene todos los derechos y libertades proclamados en esta Declaración, sin distinción alguna de raza, color, sexo, idioma, religión, opinión política o de cualquier otra índole, origen nacional o social, posición económica, nacimiento o cualquier otra condición." ... Artículo 3: "todo individuo tiene derecho a la vida, a la libertad y a la seguridad de su persona".

Afirman estos autores, que esa nueva figura de individuo contrasta con el aparato conceptual de "sujeto", propuesto desde la antigüedad clásica: "sujeto" es la traducción del latín subjectum, la cual a su vez proviene del griego hypokeimenon, herencia de Aristóteles. El sujeto aristotélico es el sustrato constante o la sustancia, es decir, la naturaleza misma del ser, su esencia, su espíritu, sobre el cual se insertan todas las cualidades, propiedades o accidentes que lo afectan y lo particularizan, desde el color de los ojos hasta las vicisitudes de su existencia, la cual es también un accidente que allí se encarna.

En esta acepción de "sujeto", el ser humano no es sujeto porque esté sometido, puesto bajo la ley de la ciudad, de la polis. Porque ser un hombre libre no se define ya por el lugar que ocupa en la ciudad como miembro pleno de la asamblea del pueblo, donde en el intercambio simbólico de palabras se define la forma correcta de practicar el intercambio de mercancías y de cuerpos en los juegos de alianza y filiación; ya no se define por el lugar que ocupa entre aquellos que están 
en el lugar de "amos" en oposición a aquellos que están en el lugar de "esclavos", excluidos de esa posibilidad de intercambio.

Ser un hombre libre se define desde entonces por el hecho de ser "dueño de sí": de sus deseos, pasiones, afectos, etc.; de todos esos "accidentes" que atraviesan el alma desde el cuerpo. Ser esclavo es estar sometido a los deseos, pasiones, afectos, etc. que corrompen el alma si uno no está vigilante. Ese cuerpo es nuestro otro, que se hace evidente en diversos movimientos, a veces como amigo o a veces como enemigo de sí mismo, según que sus imperativos nos aproximen o nos distancien del devenir que soy yo, constituyéndose por tanto en principio del cambio de sí mismo. Así, las categorías políticas de libertad y esclavitud, amo y esclavo, desaparecen detrás de las categorías morales y psicológicas de libertad individual o de servidumbre personal con respecto a las pasiones individuales que obstaculizan la felicidad, de modo que las religiones basadas en la idea de salvación, como el cristianismo, se convierten en el vector dominante de la salvación individual en Occidente.

Este deslizamiento de una acepción política a una acepción individual del ser humano, visible en términos como el libre albedrío en Tomás de Aquino, servirá de fundamento a las reflexiones posteriores de Descartes y de Kant sobre la voluntad y sobre la libertad.

En este sentido, pareciera que la mayoría de los discursos de las ciencias humanas y de las prácticas que de ellas derivan, reposan sobre el postulado de que el ser humano es un individuo. Paradójicamente, e incluso en forma creciente, continúan sin ver la contradicción, ya que el individuo es la negación de la dimensión política, pues desde el siglo xviII, por ejemplo con el contrato social de Rousseau, el acuerdo se reduce a cómo pueden vivir juntos los individuos - ya sea en pareja, familia, grupo, país, etc.-, después de que desde la infancia se les explica que su libertad personal es su bien más preciado y que no deberían obedecer sino a sí mismos. Así, esta construcción del mundo compartida por todos, dentro de la cual el otro puede ser visto como aquello que escapa a mi dominio, facilita que solo sean posibles las relaciones de dominación-dependencia, pues subyace la idea de que ser libre equivale a estar fuera de todo apego. 
Reducir al ser humano al intercambio de derechos y obligaciones con otros, es restringirlo a ser un elemento en un conjunto de interacciones, de las cuales su comportamiento es el resultado, como hacen creer las teorías que se enfocan en el esquema estímulo-respuesta, donde no hay lugar para la responsabilidad personal. Solo caben reacciones comportamentales. Otro asunto es pensar que las relaciones humanas son procesos de significación, donde los participantes se reconocen como presencias propiamente humanas, únicas e irreductibles.

En ese orden de ideas, una terapia digna de su nombre es precisamente una operación que reconoce la brecha entre el individuo y el sujeto, entre interacción y relación, para recuperar lo que han perdido los consultantes: la posibilidad de establecer entre ellos el intercambio simbólico donde cada uno recibe de los otros su lugar. Si bien los consultantes se pueden asumir inicialmente como individuos, parejas o familias donde cada miembro desempeña un rol social, también se reconoce en ellos a los sujetos con intereses particulares, dentro de los cuales caben los intereses y necesidades del sistema con el que asisten a la terapia.

Porque como dice Edgar Morin (2001), para que en las ciencias humanas el estudio del hombre realmente permita conocerlo en lugar de disolverlo, es necesario reunir y organizar los componentes de la complejidad humana - biológicos, culturales, individuales-, incorporando la reflexión filosófica centrada en el ser humano y la mirada existencial que integra y da sentido a la angustia, al gozo, al dolor y al éxtasis. Por eso el conocimiento de lo humano debe incluir información tanto introspectiva como procedente de fuentes objetivas, bajo la premisa de que cada individuo porta en sí mismo toda la condición humana. En ese sentido, el conocimiento humano debe ser a la vez científico, filosófico y poético e incluir las miradas somática, psíquica, ecológica y social.

Como el individuo es irreductible, no se puede diluir ni en la referencia a su raigambre biológica inherente a la especie, ni en la referencia a la sociedad y la cultura. Solo el individuo posee las condiciones del espíritu/mente y dispone de la conciencia y la plenitud de la subjetividad, aunque la posibilidad de la autonomía individual se actualice 
en la emergencia histórica que habita y que lo ata a un destino histórico y social. Pero el individuo opera gracias a su condición de sujeto. El sujeto representa la autoafirmación del individuo vivo que ocupa el centro de su mundo, para conocer y para actuar; y para que emerja el sujeto, no basta la diferenciación genética, anatómica, psicológica, con respecto a los demás; es necesaria la ocupación del lugar ego-céntrico por un "yo" que unifica, integra, absorbe y centraliza cerebral, mental y afectivamente las experiencias de una vida. Es decir, la cualidad de sujeto trasciende las modificaciones del ser individual.

La cualidad de sujeto garantiza la autonomía del individuo. Siempre este puede ser sometido, pero ello no significa que sea esclavo de algún poder externo, sino que una fuerza subjetiva más fuerte se impone desde el centro del programa egocéntrico y literalmente subyuga al individuo, quien se encuentra entonces poseído en el interior de sí mismo (Morin, 2001). Naturalmente, a veces ese sujeto está poseído por un Dios, un mito, una idea o una necesidad que lo esclaviza, haciendo que su identidad obedezca solo a ese referente que puede restringir su vida bajo la promesa de protección o de gratificación.

El sujeto tiene la aptitud esencial de objetivarse, reconocerse, verse a sí mismo como si fuera otro. Esa capacidad de tomar conciencia de sí, es entonces la condición para la introspección, el autoexamen y el diálogo consigo mismo.

Se asume que el sujeto es en sí mismo un sistema abierto, que opera dentro de una dinámica altamente adaptativa y está sometido a múltiples eventos que implican una reformulación continua. En ese sentido, cada persona participa con ciertas cartas que le han sido asignadas en el amplio juego de las dinámicas interaccionales que se despliegan en su contexto particular.

\section{La emergencia del sujeto y la subjetividad en la psicoterapia y la intervención sistémica}

Se entiende que la subjetividad es la expresión de un self que opera como observador de las experiencias conscientes del sujeto. Aquí, la 
subjetividad va de la mano de la reflexividad, la cual se refiere a la capacidad de autoobservación de la propia experiencia individual y de construcción de sentido en la conversación consigo mismo y con otros.

\section{La concepción de mente de Gregory Bateson}

Parece indispensable partir de las premisas propuestas por Gregory Bateson (1997) acerca de la mente y de los seres humanos, dado que son referencia indiscutible para los terapeutas sistémicos de las principales escuelas del campo.

Gregory Bateson aborda directamente el asunto del aprendizaje acerca de sí mismo. Este aprendizaje surge en los contextos vitales y por tanto ocurre en relaciones entre seres humanos; como las relaciones no están en el interior de la persona, no tiene sentido hablar de dependencia, agresividad u orgullo como características aisladas y situadas en ella, sino como resultado de observaciones que se enfocan en una sola de las personas de una relación; es decir, resultan de obviar la doble descripción que se exige para describir una relación. Cuando no se hace esa doble descripción, se asume que las características personales explican comportamientos que son relacionales, de modo que tales rasgos se convierten en principios dormitivos, como por ejemplo explicar la violencia interpersonal en los supuestos rasgos individuales de impulsividad o agresividad.

Esto no quita los aspectos autorreferenciales del conocimiento y por ello Bateson afirma que todo conocimiento exterior deriva en parte del conocimiento de sí mismo. Ahora, como dicen los budistas, el sí mismo es una suerte de ficción y por lo tanto es necesario identificar los tipos de ficciones, de modo que Bateson acepta el "sí-mismo" como un concepto heurístico, como una escalera útil para trepar, aunque tal vez haya que abandonarla después de usarla con fines específicos.

En ese sentido, Bateson se pregunta por la necesidad adaptativa de la noción de sí-mismo, pues pareciera que la mayoría de las personas puede vivir sin dar respuesta a preguntas sobre el conocimiento de sí-mismos, porque la única información necesaria para funcionar en el ambiente es relacional; es decir, la información que surge al entrar en una secuencia relacional para resolver cualquier situación. Cuando 
esa secuencia es conocida y repetitiva constituye un ritual, en el cual se puede entrar sin cuestionarse desde el sí-mismo, porque esa pauta exitosa en función del avance de las situaciones cotidianas, expresa en sus efectos pragmáticos el ajuste mutuo entre los participantes, todo lo cual constituye un marco de acción (un juego, un delito, un ceremonia, etc.), dentro del cual los humanos pueden operar fuera de la autoconciencia.

Esto no significa que la participación en esas secuencias y pautas no tenga efectos, pues en sí mismas son autovalidantes. En cuanto generan un resultado, son retroalimentación para el sí-mismo, el cual explicará sus logros como producto de su inteligencia, su autodisciplina, o su sagacidad, por ejemplo, en un proceso que combina ideas acerca del mundo y acerca de sí-mismo.

Para Bateson (1976), esa unidad total autocorrectiva que procesa la información, es decir, que piensa, actúa y decide, es un sistema cuyos límites no coinciden con los del cuerpo, ni con los del sí-mismo o la conciencia. Al contrario, desde el punto de vista cibernético, existen múltiples diferencias entre el sistema pensante y el sí mismo, como las siguientes:

1. Ese sistema cibernético no es una unidad trascendente, como se supone que es el sí-mismo.

2. Las ideas son inmanentes a una red de vías causales mediante las cuales se inducen transformaciones de diferencia. No hay impulsos sino información que surge en la diferencia.

3. Esta red de vías no está limitada por la conciencia, sino que incluye todas las vías de la mente inconsciente, tanto autónoma como reprimida, neural y hormonal.

4. La red no está limitada por la piel, sino que incluye todas las vías externas por las cuales puede viajar la información.

Por tanto, para Bateson, la mente es inmanente al cuerpo, pero la mente no es equivalente a la conciencia. Si se excluyen del sí-mismo 
los procesos inconscientes y se les llama extraños al yo, adquieren el carácter subjetivo de "impulsos", que ponen en lucha las fuerzas conscientes e inconscientes. Todo esto porque la naturaleza cibernética del "yo" y del mundo tiende a ser imperceptible para la conciencia, lo cual favorece la idea del hombre que se plantea propósitos conscientes de cambiar el mundo en vez de cambiarse a sí-mismo.

\section{Consciente e inconsciente en la hipnosis ericksoniana}

Milton Erickson (Havens, 1984) no se propuso explicar cibernéticamente su trabajo terapéutico, pero su forma de intervención se respalda en ciertas consideraciones acerca del ser humano, la primera de las cuales es la posibilidad de diferenciar, en su unicidad, la mente consciente y la mente inconsciente. La mente consciente es el estado inmediato de darse cuenta de toda información que llega a través de los sentidos.

Erickson considera que cada persona es única y por tanto merecedora de admiración y respeto tal como es; eso frena la tendencia a explicar e imponer comportamientos basándose en una sola teoría sobre el ser humano. Piensa además que el principal gozo de la vida es la libertad o autodeterminación y sentirse inepto, confundido o innecesariamente constreñido crea una ausencia de libertad ante la cual uno se resiste y reacciona con malestar. Cree que la experiencia es la fuente de aprendizaje, entendiendo que el aprendizaje es un proceso adaptativo complejo, basado en secuencias de retroalimentación desde el nacimiento.

Por lo tanto, cada individuo único intenta mantener su libertad, extendiendo su conciencia y su comprensión de la naturaleza de las reglas de su realidad, gracias al marco de referencia consciente, que experiencial y culturalmente ha construido a lo largo de su vida. Dado que su conciencia del mundo se orienta desde ese marco, perspectiva o estado de la mente, todos sus pensamientos, percepciones y respuestas dependen de dicho marco que se constituye en la fuente de toda significación.

Estas observaciones condujeron a Milton Erickson a concluir que efectivamente existen distintos niveles de conciencia y en consecuencia 
puede admitirse que existe también una mente inconsciente que percibe, piensa y responde en una forma literal u objetiva que no está limitada por las rigideces y prejuicios de la mente consciente. Puede ver cosas que ignora, descalifica o ha olvidado la mente consciente y se hace cargo de actividades complejas como caminar, conducir un carro, leer, etc.; a veces influyen los pensamientos, percepciones y conductas conscientes, aportando presentimientos intuitivos, hipótesis académicas, experiencias oníricas y respuestas emocionales. Contiene un amplio rango de capacidades y potenciales desconocidos, que permanecen inutilizados por las restricciones de la mente consciente. La mente inconsciente es un atributo universal, aunque hay gran diversidad cultural en cuanto a la comprensión y la comunicación entre los diversos niveles de consciencia (Erickson y Rossi, 2001).

En ese orden de ideas, Erickson define la conducta anormal como una conducta que no es útil a los propósitos del individuo, que surge, en general, como consecuencia de los marcos mentales conscientes rígidamente protegidos, que se resisten al aprendizaje experiencial. Por tanto, el propósito de la psicoterapia es la compleja reestructuración de las comprensiones y conductas conscientes, por medio de la creación de experiencias que simbólica o indirectamente mueven a los consultantes hacia un darse cuenta más claro de sus habilidades, pensamientos y situaciones, dentro de las condiciones únicas de cada persona. Erickson generaba experiencias internas con las palabras y experiencias externas con prescripciones conductuales, entendiendo eso sí, que el cambio es responsabilidad de los consultantes y que la psicoterapia es un proceso de aprendizaje (Gordon y Meyers-Anderson, 1981).

\section{Terapia familiar estructural}

Recuerdan Minuchin, Reiter y Borda (2014) que cuando comenzó la terapia familiar con el artículo seminal de Don Jackson publicado en 1957 sobre la homeóstasis familiar, no había teorías sobre la terapia familiar, ni mucho menos textos para comprender el funcionamiento de las familias ni de la intervención. Al contrario, los iniciadores del campo, Nathan Ackerman, Murray Bowen, Jay Haley, Don Jackson, Virginia Satir, Carl Whitaker, Lyman Wynne y el mismo Minuchin, 
desarrollaron sus comprensiones mediante los encuentros con las familias y de los análisis de esas experiencias, muchas de ellas video grabadas. Con el tiempo, esos ejemplos de aprendizaje experiencial fueron construyendo teorías sobre cómo trabajar terapéuticamente con las familias y dieron origen a institutos de formación a donde acudían a recibir entrenamiento los interesados en esta nueva forma de terapia, quienes eran principalmente terapeutas individuales provenientes de prácticas psicoanalíticas.

De hecho, a Minuchin le preocupa que la actual formación de terapeutas, al entrar en la lógica académica de las universidades, haya pasado del aprendizaje inductivo desde la experiencia terapéutica, al deductivo que aplica a los consultantes la teoría expuesta en los libros, porque esto conduce a cierta asepsia en el estilo de los terapeutas, quienes operan conceptos y técnicas que los excluyen a sí mismos como instrumentos de cambio en la intervención y al contrario enfatizan la búsqueda de explicaciones que no implican la exploración de nuevas alternativas ni el cuestionamiento movilizador.

Minuchin (1977) dice que en los años setenta surgieron en Estados Unidos tres corrientes de terapia familiar: la que él llama transicional, de procedencia psicodinámica, cuyo objetivo es la reestructuración psicológica del paciente, hace énfasis en el pasado y en el contenido de la comunicación y usa la interpretación y la transferencia como dispositivos de cambio. A la segunda la llama corriente existencial, cuyo objetivo es la expansión y el crecimiento de la persona, hace énfasis en el presente y acude a esa experiencia del sujeto y la familia como instrumento de cambio. Él se ubica en la tercera corriente, cuyo objetivo es el cambio del sistema familiar como contexto social y psicológico de los miembros de la familia y cuyo énfasis está en la transformación de los procesos interpersonales.

La terapia estructural de la familia constituye un cuerpo de teoría y técnicas que estudian al individuo en su contexto social; intenta transformar la estructura del grupo familiar con la premisa de que al modificarse las posiciones de los miembros de este grupo, se modifican las experiencias de cada individuo, las cuales están determinadas por su interacción con el medio. Las técnicas tradicionales de salud 
mental se concentran en la exploración de la vida intrapsíquica y trabajan con cada persona individualmente, como si existiera una frontera artificial entre el individuo y su contexto, lo cual ha llevado a ver al individuo como el asiento de la patología. Por el contrario, la terapia estructural convoca a todos los miembros de la familia, de modo que puede moverse en la misma escena desde el foco individual al foco interaccional más amplio, observando directamente ese proceso, y no solo la visión internalizada por cada miembro.

Es importante recordar que, inmersa en la teoría de sistemas, la terapia familiar estructural considera que

La estructura familiar es el conjunto invisible de demandas funcionales que organizan los modos en que interactúan los miembros de una familia.... Las transacciones repetidas establecen pautas acerca de cómo, cuándo y con quién relacionarse y esas pautas apuntalan el sistema. (1977, p.86)

En este sentido, la estructura familiar no es una realidad inmediatamente observable, sino que el terapeuta, al asociarse con la familia, analiza el campo transaccional para lograr así un diagnóstico estructural y un mapa familiar que le permiten formular hipótesis sobre las pautas operativas y las ineficaces y obstaculizadoras.

El terapeuta estructural asume que no existe una personalidad esencial, sino que como miembro de distintos contextos sociales, el individuo va cambiando constantemente, inclusive porque su cerebro procesa e integra todas sus experiencias, internas y externas. La terapia estructural se basa en tres axiomas: 1) La vida psíquica no es exclusivamente un proceso interno; el individuo influye en su contexto y es influido por este, en secuencias repetidas de interacción, como parte de su proceso adaptativo. 2) Las modificaciones en la estructura familiar contribuyen a que haya cambios en la conducta y en los procesos psíquicos internos de los miembros de este sistema. 3) Cuando un terapeuta trabaja con un paciente o una familia, su conducta se incluye en ese contexto; es decir, el terapeuta y la familia forman un nuevo sistema, 
cuyo funcionamiento incide en la conducta de sus miembros. El terapeuta se asocia con la familia con el fin de cambiar su organización de modo que se modifique la experiencia subjetiva de sus miembros.

En esta estructura teorética no se ignora al individuo. El presente del individuo es su pasado más sus circunstancias actuales. ... El hombre tiene memoria; es el producto de su pasado. Al mismo tiempo, sus interacciones en sus circunstancias actuales apoyan, califican o modifican su experiencia. (Minuchin, 1977, p.37)

De hecho, cuando uno trata con la memoria, no solo cambia la manera en que la persona observa el presente; también reacomoda el pasado. El error de algunos terapeutas es creer en la inmutabilidad de los recuerdos. Al contrario, siempre creamos recuerdos, como parte de un proceso normal y natural. Por tanto, lo que no puede ser cierto, es que una vez que esos recuerdos aparecen en terapia, representan la verdad o la realidad. Los terapeutas deben ser cuidadosos de no ver a los recuerdos como una verdad inmutable (Minuchin, en Simon, 1996/7).

La familia es entonces la matriz de la identidad del individuo, mediante procesos recíprocos de individuación y de acomodación a la sociedad, para garantizar la continuidad de la cultura. En este sentido, el individuo es en sí mismo un subsistema de la familia, encara distintas tareas y adquiere variadas habilidades interpersonales en los diferentes subsistemas.

Desde el punto de vista de los dispositivos de cambio a los que acude, la terapia estructural es una terapia de acción. El terapeuta se une a la familia no para educarla o socializarla, sino para reparar o modificar su funcionamiento, en forma cuidadosamente planificada, para que la familia pueda realizar sus tareas con mayor eficacia, entendiendo que, en cuanto sistema, opera por mecanismos de autorregulación, los cuales le permiten mantener sus cambios en ausencia del terapeuta. Para transformar a la familia, el terapeuta debe actuar de modo que se desequilibre el sistema, para lo cual la confianza de la familia en él es fundamental; el terapeuta por su parte motiva a los 
miembros de la familia en la dirección de los objetivos terapéuticos mientras soportan las incertidumbres del desequilibrio, les ratifica su apoyo y da reconocimiento a las necesidades de cada uno.

Así, el terapeuta se usa a sí mismo como recurso terapéutico, aunque finalmente asume que "la familia es la matriz de la curación" (Minuchin, 1977, p.174). El terapeuta cuestiona la percepción de la realidad de los pacientes, les dice que sus experiencias son discutibles y "corroe la certeza de cada miembro de la familia acerca de la validez de su experiencia” (p.175), pues el terapeuta sabe que la realidad es más compleja, los cuestiona basándose en la consideración de que puede ver más allá de ellos y se aferra a la posibilidad de nuevas alternativas de experiencia y a códigos alternativos. No obstante, lo que plantea debe formar parte del repertorio existente de los miembros de la familia.

En síntesis, Minuchin afirma que los pacientes evolucionan por tres causas: porque se cuestiona su percepción de la realidad, se les proporcionan posibilidades alternativas que les parezcan adecuadas y una vez ensayan estas pautas alternativas, aparecen nuevas relaciones que se refuerzan a sí mismas. A su vez remarca que su estilo terapéutico se organiza alrededor de dos parámetros: cómo preservar la individuación y cómo apoyar la reciprocidad.

También insiste en que es vital proporcionarles apoyo para que pasen de una posición a la siguiente, entendiendo que el contacto terapéutico se produce en un nivel de proximidad interpersonal en un contexto específico y que el contenido de cada sesión depende de factores idiosincráticos, tanto del estilo de interacción de la familia como de la personalidad del terapeuta, quien actúa siempre en conformidad con sus propias experiencias vitales. De hecho, reconoce muy honestamente:

A través de los años logré un cierto número de éxitos y cometí innumerables errores, que me proporcionaron un sentido de competencia y autoridad. En mis peores momentos, este sentido de realización se expresa en una posición autoritaria, y en otras ocasiones me permite actuar como un experto. En la medida en que aprendí a aceptarme y a reconocer áreas en las que nunca cambiaré, desarrollé un sentido de respeto por la diversidad de los enfoques de la gente ante los problemas humanos. (Minuchin, 1977, p.179) 
He aprendido a deslindar a mi persona de la situación y a orientar a los miembros de la familia para que actúen su propio drama mientras yo observo. Soy espontáneo en mis intervenciones, ya que he aprendido a confiar mis respuestas a las familias. Observo continuamente el orden y el ritmo de las comunicaciones de la familia, decidiendo en forma consciente acerca del momento en que debo hablar y de la persona a la que debo dirigirme. Como terapeuta, tiendo a actuar como un pariente lejano. ... Intento asimilar el lenguaje de la familia y sus mitos. (Minuchin, 1977, p.183)

En coherencia con estos planteamientos, afirma que es desde su posición de liderazgo, como el terapeuta mantiene su posibilidad de maniobra terapéutica y su libertad para manipularse a sí mismo y para manipular a la familia. Reconoce la connotación negativa de la idea de "manipular", pero también que las familias acuden porque sufren y necesitan ayuda, la cual consiste en realizar con la familia operaciones que faciliten su evolución, asumiendo además que el contrato terapéutico incluye la posición del terapeuta como un experto en la manipulación experimental social.

Específicamente, Minuchin y Fishman (1981) plantean que la noción de holón individual incorpora el concepto de self-en-contexto. Esto incluye los determinantes personales e históricos del self, los cuales operan en un proceso circular continuo de mutua afectación y reforzamiento, que tiende a mantener una pauta fija, aunque simultáneamente, tanto el individuo como el contexto tienen la capacidad de cambio y flexibilidad. Como el individuo participa en varios contextos, la constante interacción en diferentes holones, requiere la actualización de diferentes segmentos del self.

Por otra parte, la terapia familiar estructural considera que los pacientes buscan ayuda porque la realidad, tal como ellos la han construido, es inmanejable, y por lo tanto, en este sentido, todos los tipos de terapia dependen del desafío a esos constructos. Para esto se fundamenta ampliamente en los planteamientos de los sociólogos constructivistas P. Berger y T. Luckman, citados en varias oportunidades en el texto Técnicas de terapia familiar. Así, esta terapia postula que las 
pautas transaccionales dependen y contienen la forma como las personas experimentan la realidad, por lo cual, cambiar esa visión, requiere activar un nuevo estilo de interacción, mediante técnicas como el desafío de los constructos cognitivos, las intervenciones paradójicas y el énfasis en las fortalezas (Minuchin y Fishman, 1981).

Todo esto implica la premisa de que los humanos son narradores, constructores de mitos y enmarcadores de realidades y para desafiar esas construcciones el terapeuta aplica además las técnicas de actuación, focalización e intensificación. Es decir, genera escenas donde la familia "danza" sus pautas en presencia del terapeuta; elige un tópico, profundiza la conversación en él y le pone volumen a ciertos mensajes que quiere trasmitir a la familia, con el fin de que lo asimilen dentro de su esquema cognitivo como nueva información. Todo esto porque el terapeuta estructural considera que las construcciones cognitivas per se son poco potentes para activar el cambio en la familia.

Se reconoce que la nueva realidad familiar es una construcción terapéutica, pero dicha novedad está restringida por la propia biografía del terapeuta, las condiciones finitas que vive la familia y la forma idiosincrática como ella desarrolla su estructura. No obstante, la meta terapéutica es siempre llevar a la familia a una cosmovisión diferente, donde no sea necesario el síntoma, y por el contrario tenga una visión más flexible y pluralista.

\section{Terapia estratégica breve del Mental Research Institute}

En Teoría de la comunicación humana (Watzlawick, Beavin \& Jackson, 1967, 1981), Carlos Sluzki recuerda que cuando para el estudio de la conducta humana se pasa del énfasis en las intenciones al énfasis en los efectos de los actos, se opera un cambio cualitativo que afecta la visión del mundo y se pasa de los procesos intrapsíquicos a los procesos interaccionales que inscriben y dan sentido a la conducta del individuo en su contexto. A su vez, los autores afirman que desde esta óptica, el observador de la conducta humana pasa de un estudio deductivo de la mente, al estudio de las manifestaciones observables de la relación; el vehículo de tales manifestaciones es la comunicación, uno de cuyos 
componentes inherentes es el contexto. Así toda conducta es comunicación y toda comunicación afecta la conducta.

En ese momento, 1967, Watzlawick, Beavin \& Jackson, puntualizaron que las percepciones dependen de un punto de referencia, porque como ya lo mostraban las investigaciones sobre los sentidos y el cerebro, solo se pueden percibir relaciones y pautas de relaciones, las cuales constituyen la esencia de la experiencia que el hombre tiene de la realidad. Por ejemplo, un sonido constante e invariable es difícil de percibir y puede volverse inaudible. Por otra parte, "incluso nuestra autoconciencia depende de la comunicación: para comprenderse a sí mismo, el hombre necesita que otro lo comprenda. Para que otro lo comprenda, necesita comprender a ese otro" (Watzlawick, Beavin \& Jackson, 1967, p.37). El problema ha sido que no ha habido posibilidades ni métodos para comunicarnos acerca de la comunicación, por lo cual su trabajo se orientó a la comprensión de las configuraciones inherentes a la interacción humana. Porque las propias de reglas de conducta e interacción pueden expresarse en distintos grados de conciencia, pues entre más abstractas son las premisas que fundamentan las configuraciones, menos son accesibles a la conciencia.

No obstante, ello no significa que no sean relativamente evidentes para el observador externo, quien puede por ejemplo inferir, hipotéticamente, las reglas del juego de ajedrez, al identificar los movimientos repetitivos entre los jugadores, los cuales constituyen configuraciones estructuradas conforme a las reglas del juego. Además, existe la capacidad de metacomunicación, la cual es una condición sine qua non de la comunicación eficaz, íntimamente vinculada con la percepción del self y del otro. Esta noción corresponde al axioma de la comunicación humana según el cual toda comunicación tiene un aspecto de contenido y un aspecto relacional, de modo que el segundo clasifica al primero y es por ende una metacomunicación.

La definición de la naturaleza de la relación implica una definición de sí mismo y toda expresión de ideas o actividad simbólica, por y para sí misma corresponde a la función de reconstruir constantemente el concepto de self, de ofrecer dicho concepto a otros para obtener ratificación y aceptar o rechazar esa misma actitud en los demás, de 
modo que cada encuentro favorece una forma de autoconciencia incrementada de sí mismo.

En otras palabras, cada intercambio implica una expresión de "así es como me veo". Ante esta autodefinición, el interlocutor puede dar tres tipos de respuesta: confirmarla y aceptarla; rechazarla y negarla, o desconfirmarla. Esto último no se refiere a la verdad o falsedad de esa autodefinición, sino que significa negar la existencia de quien emite esa definición. Es decir, si el rechazo equivale a decir "estás equivocado", la desconfirmación afirma "tú no existes". Esas tres respuestas encarnan la expresión por parte del otro de "así es como te veo". Esa secuencia de aceptaciones, rechazos o desconfirmaciones puede continuar, al menos teóricamente ad infinitum, con mensajes que se expresarían como "así es como veo que tú me ves” y "así es como veo que tú ves que yo te veo". Este proceso que muestra los niveles de percepción interpersonal, equivale a los llamados procesos reflexivos.

En la realidad interpersonal cotidiana, mi "yo" está enfrentado con un Alter, y desde el punto de vista del Alter, mi "yo" es su Alter. Por tanto, sobre todo en las relaciones más significativas, la visión que el otro tiene de mí es tan importante como la visión que tengo de mí mismo, pero en el mejor de los casos ambas visiones son solo más o menos similares. Este "más o menos" determina la naturaleza de nuestra relación y, en consecuencia, mi sensación y la del otro de ser entendidos y tener una identidad. Si cada participante en la interacción tiene una visión diferente, sobre la cual no se puede metacomunicar, aparece lo que Watzlawick, Beavin \& Jackson (1967) llaman impenetrabilidad, fenómeno difícil de resolver desde el punto de vista terapéutico, porque finalmente las relaciones no son realidades sino experiencias puramente subjetivas o construcciones hipotéticas. Es decir, las relaciones no son realidades en el mismo sentido que los objetos tangibles, que están ahí afuera; en las relaciones estamos contenidos, solo somos parte de un todo más amplio que no podemos captar por los sentidos, del mismo modo que es imposible tener una visión completa del propio cuerpo porque los ojos son parte del cuerpo que se desea observar. Por tanto, la desconfirmación sistemática en una relación, lleva a que Ego y Alter se enfrenten en una creciente alienación de naturaleza 
interpersonal, que está más allá de la percepción individual y cuyos efectos se le atribuyen al otro.

En ese sentido, la psicoterapia se ocupa de favorecer la metacomunicación y de "traducir" o digitalizar de nuevas formas, tanto el contenido como los ingredientes analógicos que encarnan la naturaleza de las relaciones, para hacerlas menos angustiantes y más adecuadas al contexto y a las necesidades individuales de validación del self.

Watzlawick, Beavin \& Jackson (1967) aclaran que, dado que la psicología y la psiquiatría son disciplinas autorreflexivas, en cuanto a que la mente se estudia a sí misma y por ello tiende a autovalidarse, escogieron el concepto de "caja negra” para investigar la comunicación humana porque ofrece la ventaja heurística de no tener que recurrir a ninguna hipótesis intrapsíquica imposible de verificar y en cambio permite limitarse a las relaciones observables de entradas y salidas, es decir, a la comunicación.

En este enfoque, los síntomas son una de las múltiples formas de entrada al sistema familiar y no una expresión de conflictos intrapsíquicos. Estos autores reconocen la importancia de diferenciar si una conducta es consciente, inconsciente, voluntaria, involuntaria o sintomática, y admiten que la atribución de significado es una noción esencial para la experiencia subjetiva de comunicarse con otros, pero objetivamente imposible de determinar a los fines de la investigación sobre la comunicación humana.

Admiten también que, si bien no cabe duda de que la conducta es determinada, por lo menos en parte, por la experiencia previa, la búsqueda de causas en el pasado no es fidedigna, pues la memoria es una construcción hipotética, basada principalmente en pruebas subjetivas. Por eso este enfoque constituye la búsqueda de configuraciones en el aquí y ahora, más que de significaciones simbólicas, causas o motivaciones pasadas. Esto implica además que la noción de anormalidad es cuestionable, porque el estado de los pacientes no es estático y varía según la situación interpersonal y la perspectiva subjetiva del observador.

En el Epílogo de Teoría de la comunicación bumana (1967), titulado El existencialismo y la teoría de la comunicación humana: un enfoque, los autores afirman que la concepción del hombre solo como 
un ser social no logra explicarlo en su nexo existencial, del cual la participación social es apenas un aspecto. Se preguntan entonces de qué manera la teoría de la pragmática de la comunicación sirve para transitar de lo interpersonal a lo existencial y de qué forma, entendiendo que para desarrollar este tema deben pasar del dominio de la ciencia a una actitud reconocidamente subjetiva. Porque como el hombre no puede ir más allá de los límites fijados por su propia mente, sujeto y objeto son idénticos cuando la mente se estudia a sí misma, de manera que cualquier aseveración del hombre en su nexo existencial puede llevar a los mismos fenómenos de autorreflexividad que generan la paradoja. En todo caso, estos planteamientos, dicen los autores, expresan la creencia de que el hombre existe en una relación amplia, compleja y privada con la vida.

En ese sentido,

la vida (o la realidad, el destino, Dios, la naturaleza, la existencia, o cualquiera sea el nombre que prefiera dársele) es un socio al que aceptamos o rechazamos, y por el cual nos sentimos aceptados o rechazados, apoyados o traicionados. A este socio existencial, quizá tanto como ocurriría con un socio humano, el hombre propone su definición del self y la ve luego confirmada o desconfirmada. (Watzlawick, Beavin \& Jackson, 1967, p.237)

Para asegurar su supervivencia como ser humano, el hombre crea conocimiento de primer orden, de las cosas; de segundo orden, acerca de las cosas, y de tercer orden, o conocimiento acerca del conocimiento de segundo orden. En el humano adulto, el conocimiento de primer orden rara vez se da solo, porque siempre busca comprender el significado que los objetos tienen para su existencia y reacciona ante ellos según esa comprensión. A su vez, de la suma total de los significados que ha deducido mediante sus contactos con numerosos objetos de su medio, surge una visión unificada del mundo en la que se ve a sí mismo, visión que es de tercer orden. Esa visión incluye una serie de premisas acerca de los fenómenos que percibe, las cuales condicionan su interacción con la realidad. Porque para los humanos, la manera específica de ser-en-el mundo es el resultado de su elección; es 
el significado que le confieren a lo que quizá está más allá de la comprensión humana objetiva.

El asunto es que esas premisas de tercer orden no son absolutamente congruentes con las realidades vividas y así surgen los problemas emocionales y existenciales. En ese caso, la psicoterapia se comprende como un dispositivo para revisar y reformular las premisas de tercer orden, convirtiéndose en una forma de construcción de conocimiento de cuarto orden.

Vista así, "nuestra experiencia subjetiva de la existencia es la realidad y esa realidad es nuestra manera de pautar algo que quizá esté más allá de toda verificación humana objetiva" (Watzlawick, Beavin \& Jackson, 1967, p.244). Esa es la paradoja de la existencia humana, donde el hombre es sujeto y objeto de su búsqueda, parte del mundo y límite del mundo.

Como puede apreciarse, no es que Watzlawick, Beavin \& Jackson nieguen la existencia de la subjetividad y de los procesos de significación. Lo que ocurre es que al comprender el psiquismo como una emergencia sistémica y al elegir para efectos investigativos y de cambio la opción heurística de la "caja negra", pasaron del foco del "por qué ocurre" al "qué ocurre", con lo cual saltaron de la búsqueda del origen y de las explicaciones causales en el pasado, a la identificación de los procesos sistémicos dentro de los cuales surgen tanto los problemas como las soluciones. Esto llevó por tanto a que la psicoterapia se orientara más al cambio de las pautas de interacción que al insigth o comprensión como condición de resolución de los problemas, lo cual ha alimentado la connotación conductista y manipuladora de la terapia propuesta por el grupo de Palo Alto.

No obstante, si se comprenden los fundamentos de la teoría de la comunicación humana, queda claro que si los problemas se ven como producto de las confusiones entre órdenes de conocimiento y de realidad, y las soluciones como las nuevas opciones de organización de la visión de la realidad, adquiere sentido el uso de las técnicas paradójicas como vehículo de cambio en la conversación psicoterapéutica. Para asimilar esta perspectiva es también indispensable aceptar el carácter no consciente del efecto de sistema inherente a la interacción humana, 
donde se entremezclan los lenguajes digital y analógico, a los cuales les corresponden dos concepciones del mundo distintas, porque el lenguaje, más que reflejar una realidad, crea una realidad (Watzlawick, 1980).

Como afirman Jacques y Laurent (2006), al optar por una aproximación constructivista que pone el acento en el sujeto observante, la cibernética definida por von Foerster ha reconocido la subjetividad del sistema y el retorno a la irreductibilidad del sí mismo individual y autónomo.

\section{La terapia posmoderna}

Para justificar el interés de la terapia posmoderna, dice Lynn Hoffman (en Anderson, 1999, p.16) que la terapia familiar fue la plataforma desde donde se apreciaron los defectos de la terapia individual; la terapia sistémica, la plataforma desde donde se criticó el trabajo con familias; la terapia basada en nociones de género, una plataforma desde donde se vio la distorsión patriarcal del trabajo sistémico y la terapia narrativa, la plataforma para ver cómo los discursos de clase, raza y cultura oprimen a la gente. A su vez Anderson aclara que el marco filosófico donde fundamenta su enfoque colaborativo de los sistemas de lenguaje es el construccionismo social, la hermenéutica y la narrativa posmodernas. Concibe la terapia como "un sistema de lenguaje y un acontecimiento lingüístico que reúne a la gente en una relación y una conversación colaborativas - una búsqueda conjunta de posibilidades" (en Anderson, 1999, p.28).

Anderson (1999) explicita que su enfoque se apoya en pensadores que criticaron la autoridad científica como base del conocimiento y ofrecieron otros criterios para comprender la psicología humana. Como advierte en el cierre del libro (p.344) que por supuesto sus planteamientos no son la verdad, sino la descripción y la explicación actual de su experiencia, se cuida de comunicar desde el principio sus principales premisas filosóficas. Estas se refieren a que los sistemas humanos son sistemas de generación de lenguaje y de sentido; son más formas de acción social que procesos mentales individuales independientes, porque 
la mente individual es un compuesto social relacional; la realidad y el sentido que atribuimos a las experiencias son fenómenos interaccionales creados y vivenciados por individuos en una conversación y acción con otros; el lenguaje es generador, da orden y sentido a la vida y opera como una forma de participación social; por tanto, el conocimiento es relacional.

Sin especificar sus referentes, Anderson hace una dicotomía con tintes valorativos e ideológicos entre terapeutas que dirigen la terapia desde una organización y unos procesos jerárquicos y terapeutas que tienen una postura filosófica terapéutica que invita a una relación y un proceso colaborativo; una dicotomía que pretende diluir un sistema que ella designa como definido por una estructura de roles, para pasar a un sistema basado en el contexto y producto de la comunicación social, dentro del cual se diluye también la dualidad experto-no experto para pasar a una sociedad colectiva entre personas con diferentes perspectivas y conocimientos; este terapeuta conduce una indagación compartida que depende de las capacidades de todos los participantes, en lugar de ser intervencionista, con capacidad estratégica y técnica.

Anderson (1999, p.48) concluye al hacer un análisis de los desarrollos de la terapia familiar propuesta por el grupo de Palo Alto, que la cibernética de primer orden fue el común denominador de las escuelas cuyo tema de fondo era la retroalimentación correctora de desviaciones, activada por errores, en coherencia con el cual la meta de la terapia era interrumpir la homeostasis y promover el cambio y afirma que "buena parte de la terapia familiar ha ignorado ingenuamente al individuo o lo ha abandonado intencionalmente, perdiendo así la experiencia individual, y ha separado al "yo" y al "tú", perdiendo asî la dimensión relacional de la identidad" (Anderson, 1999, p.60). Por ello llega al posmodernismo, aduciendo allí que el individuo y la relación se mueven a un primer plano, desde otras conceptualizaciones, de modo que ahora destacan la contextualización social o relacional de la realidad. Ella considera que en la terapia familiar el individuo y la familia han sido dicotomizados y pretende mostrar como innovación, que el foco no es el individuo ni la familia, sino la persona-en-relación. 
Lynn Anderson (en H. Anderson, 1999, p.66) afirma que,

La terapia modernista es un proyecto liderado por el terapeuta, influido por las verdades dominantes de la cultura y que conduce a posibilidades determinadas por el terapeuta... A medida que el pre-conocimiento y la voz monovocal se forman, los resultantes pensamientos y acciones del terapeuta tienden a dominar y silenciar la voz del cliente. Creo firmemente que privilegiar nuestras voces de terapeutas contribuye a perpetuar la desigualdad institucional, tanto en el nivel local de la relación terapeuta-cliente, como en el nivel universal de la relación individuo-familia-sociedad, por ejemplo al ignorar o apoyar generalizaciones sexistas, racistas o relacionadas con la edad.

Para contraponerse a esa visión acude entonces como referentes a la hermenéutica filosófica contemporánea y al construccionismo social, los cuales afirma que sí ven a los sistemas humanos como entidades complejas integradas por individuos que piensan, interpretan y comprenden. Las acoge además porque ambas cuestionan la aplicación de explicaciones tradicionales de las ciencias físicas y naturales, al análisis de los sistemas humanos y considera que la precomprensión inherente a tales explicaciones no permite apreciar la complejidad de lo humano. La hermenéutica se ocupa de la comprensión del significado de un texto o discurso, incluidas la emoción y la conducta humanas, entendiendo que toda comprensión es interpretativa y por lo tanto influida por las creencias, los supuestos y las intenciones del intérprete.

Por otra parte, Anderson establece distinciones entre el constructivismo y el construccionismo social. Reconoce que su punto en común es su definición del conocimiento y de la realidad como una construcción. Las diferencias parten de sus orígenes, pues el constructivismo integra las apuestas de J. Piaget, G. Kelly y los cibernetistas H. von Foerster, E. von Glaserfeld, P. Watzlawick y H. Maturana, pero sobre todo se manifiestan en que desde el constructivismo radical la realidad es una construcción de la mente y pone el acento en la autonomía del ser como constructor de sentido, reconociendo el papel crítico de las 
estructuras biológicas del sujeto cognoscente, lo cual es calificado por Gergen (1996) como expresión del individualismo occidental.

Por contraste, el construccionismo social toma distancia de la idea de la mente constructora individual y cuestiona la noción del individuo autónomo. El individuo no es el objeto discreto de comprensión, ni el creador de sentido; es el contexto interaccional y comunal el que produce significación, la mente es relacional y el desarrollo del sentido es discursivo. El contexto es concebido como un dominio multirrelacional y lingüístico, donde las conductas, los sentimientos, las emociones y las comprensiones son comunales, porque ocurren en una pluralidad compleja y cambiante de redes de relaciones y procesos sociales.

En el posmodernismo, el sí mismo es narrativo, partiendo de que la narrativa es una forma de discurso, una forma de organizar, dar sentido, comprender, dar estructura y coherencia a las circunstancias y procesos de la propia vida. Es una descripción de lo que hacemos y un proceso discursivo reflexivo, cuyo vehículo es el proceso de lenguaje, en conversaciones con otros y consigo mismo. En ese sentido, el "yo" no existe fuera del lenguaje ni del discurso, sino que se crea y se sostiene en él. El "yo" es un sujeto hablante (Gergen, 1996). Desde la perspectiva narrativa, el propio ser, el narrador, es muchos "yo", ocupa muchas posiciones y tiene muchas voces que actúan como los personajes interactuantes de una historia.

La acepción del "yo" como cuentista implica la idea de que la historia es algo creado dentro del "yo", de modo que la psicoterapia es un suceso historiado, donde, dado que tanto el "yo" como la terapia son procesos dialógicos y sociales, la narrativa se crea fuera del "yo". En el centro de las narrativas que emergen en el curso de la organización de la conducta, se ubican aquellas que contienen elementos articulados en forma de historias propias o narrativas en primera persona, las cuales conducen a que la identidad adquiera una forma narrativa. Así, el "yo" vendría siendo un producto del lenguaje, un "yo" implícito de decires autorreferentes... y el sujeto el resultado de una praxis discursiva (Gergen, 1996). El "yo" es entonces un configurar sucesos personales en una unidad histórica que incluye lo que uno ha sido y 
anticipaciones de lo que será. Pero en esa versión del "yo", participan muchas voces, de donde surge la idea de una identidad polifónica.

Citando a Gergen (1994), Anderson (1999) admite la sugerencia de que lo individual es una propiedad que emerge de lo comunitario, donde la relación precede a la identidad, teniendo en cuenta, eso sí, que participan el "yo" y el "tú", porque las narrativas que cuento sobre ti son parte del proceso de tu identidad y viceversa. Siendo así, se subraya la responsabilidad de psicoterapeutas y profesionales de las ciencias humanas y sociales, pues si el lenguaje no es representacional sino formante, configurador, somos responsables por el modo en que lo usamos, las palabras que elegimos y la influencia de estas decisiones en el relato que emerge, el que es privilegiado y el que se considera verdadero; más aún cuando el observador no tiene acceso a la experiencia individual, sino que el relato es la unidad de análisis. En ese sentido, dado que el relato ya no está ligado al individuo que lo proporcionó, los investigadores pueden usarlo como tal y conectarlo con la búsqueda de otros relatos similares en el medio sociocultural, las ideologías con las que se asocian y los intereses políticos que los apoyan o los atacan (Anderson, 1999).

A través de esas narrativas devenimos agentes o actores y damos un sentido a lo social y a la autonomía, entendida como una percepción personal de competencia para la acción intencional, que implica la capacidad de elegir de manera liberadora y creadora. Por tanto, el propósito de la terapia es ayudar a que los consultantes cuenten sus narrativas en primera persona y transformen sus identidades para ganar creatividad y sentido de autonomía.

Si se acepta la sugerencia de Mary Catherine Bateson (1994), acerca de que el reto en este mundo interpersonal es separar la noción de diferencia de la noción de superioridad y hacer de lo no familiar un recurso más que una amenaza, los enfoques expuestos pueden ser vistos como puertas de entrada al universo de los sujetos, donde el encuentro de las salidas no necesariamente está garantizado por un recorrido sugerido por los autores, sino que al contrario parece un final que permanece abierto, conforme varían las experiencias de quienes deciden seguir esas rutas inciertas y laberínticas del sí mismo. 